\title{
Trajetórias, Formas de Conjugalidade e Relações Sociais de Gênero entre Casais Binacionais
}

\author{
Trajectories, ways of marriage and social relations of gender among binational \\ couples.
}

\author{
Maria das Graças Lucena de Medeiros \\ Universidade Federal do Rio Grande do Norte \\ gracamedeiros@digizap.com.br
}

\section{Resumo}

Processos socioeconômicos e tecnológicos a partir dos anos 70, século XX afetaram instituições sociais, como o casamento e a família. A fragmentação, a efemeridade e o caótico, aumentaram violentamente de intensidade num contexto que se tornaria globalizado. Analisa-se resultados referentes à relação entre conjugalidade e mudança social, o desvendar dos efeitos do Turismo Afetivo que explicita a reconstituição de arranjos familiares, dinâmicas, trajetórias, relações sociais de gênero, entre Casais Binacionais na cidade de Natal, Nordeste Brasileiro.

Palavras Chaves: Família; Conjugalidade; Gênero; Migração; Interculturalidade

\begin{abstract}
Socioeconomic and technological processes from the seventies, twentieth century, have affected social institutions, like marriage and family. The fragmentation, the ephemerality and the chaotic were greatly increased in a context that would become globalized. The results are analyzed regarding the relationship between marital and social change, the unveiling of the Affective Tourism effects that make explicit the reconstitution of family arrangements, dynamics, trajectories and social relationships of gender among binational couples in the city of Natal, Northeast Brazil.
\end{abstract}

Keywords: Family, Conjugality, Gender, Migration, Interculturality 


\section{Trajetórias, Formas de Conjugalidade e Relações Sociais de Gênero entre Casais Binacionais}

O que se constatou, neste estudo, fruto de minha tese de Doutorado, é a confirmação de uma tendência generalizante a uma busca de novas formas de conjugalidade, já que o modelo de família tradicional patriarcal e hierarquizante - está cada vez mais incoerente com os outros valores da sociedade, seja em se tratando de manifestações culturais, seja em se tratando de economia e política. Não se trata de, como é comumente chamada, uma simples "crise do casamento contemporâneo": dados mostram que as pessoas ainda buscam sua felicidade através do casamento, apesar do grande aumento no número de divórcios. Sobre isso, Carvalho Filho, escreve que:

O que constatamos é que os indivíduos têm se divorciado, não por considerarem o casamento menos importante, mas, justamente, porque sua importância é tão grande que eles não aceitam que a vida conjugal não corresponda às suas expectativas. (CARVALHO FILHO, 2000. p. 45)

Com o aumento das separações, crescem também, em número e em diversidade, as novas configurações familiares.

\section{Novas (vellhas) Formas de Conjugalidade}

O casamento tem assumido formas novas e variadas, que podem tanto ser vistas como um sinal de falência, ou como uma tentativa de se ultrapassar um modelo que não estaria coerente com as rápidas transformações que acometem o homem contemporâneo.

Nicolaci-da-Costa sugere que o processo de transformação social é tão acelerado que muitas vezes "temos a sensação de estarmos à deriva, pois aquilo que conhecíamos como o 'nosso mundo' deixou de existir" (NICOLACI-DA-COSTA, 1985. p. 98). A autora coloca que esta sensação é comum a vários processos de transformação em que se inicia um processo de desestabilização dos modos tradicionais de viver. O sujeito perde os seus referenciais e se vê perdido em um excesso de liberdade, desorientado e sem regras claras para seguir.

Parece que estamos vivenciando o intervalo entre a queda de padrões tradicionais e rígidos e a construção de novos modelos de casamento. O que a autora questiona é "se o efêmero, o fragmentário, o descontínuo e o caótico não geram, no indivíduo pósmoderno, os sentimentos de insegurança e de estar à deriva" (NICOLACI-DA-COSTA, 1985. p. 98). Acreditando que sim, e que as transformações sociais repercutem de forma muito direta nos projetos de vida individuais, temos que o sujeito contemporâneo é dominado por uma incerteza, fruto da perda dos referenciais sólidos e da necessidade de buscar novos padrões, aparentemente ainda não construídos. Deste modo, os novos arranjos matrimoniais fazem parte de um contexto social em reorganização (especialmente se pensarmos que a família não é um fato natural, mas sim uma construção cultural).

O casal contemporâneo depara-se com uma série de possibilidades de viver a sua conjugalidade, muitas delas que em nada se aproximam com o que costumamos chamar de casamento tradicional. Goldani (1993), refere-se, como novos modelos possíveis de se viver a conjugalidade, a casais que decidem viver junto sem legalizar ou oficializar seu relacionamento; casais que vivem em diferentes locais; homens ou mulheres que preferem ter filhos e permanecer solteiros, prática que costuma ser chamada hoje de 'produção independente'; casais homossexuais com filhos através da adoção ou da inseminação artificial, para citar alguns dos possíveis arranjos. A mesma autora, reforça que muitas dessas pessoas, que optam por viver estes novos arranjos, costumam chamar seus parceiros de esposo/marido ou esposa/mulher, não só pela ausência de um melhor termo que defina o tipo de relacionamento, mas também pelo preconceito social ainda existente.

Em relação aos recasamentos, há um aspecto que merece ser destacado: os homens têm mais facilidade em encontrar novas parceiras do que as mulheres novos parceiros. É o fenômeno que Berquó (1989) chama de 'pirâmide da solidão': na medida em que envelhecem, as mulheres vêem sua chance de recasar diminuindo. Isto se deve, em parte, à maior estimativa de vida que as mulheres possuem, e, certamente, com maior relevância, ao fato de que os homens costumam se recasar com mulheres bem mais novas, o que é socialmente aceito - já a recíproca não é verdadeira. Assim, o número de homens não casados permanece estável, enquanto o número de mulheres sem nenhum tipo de união aumenta cada vez mais. Outra diferença singular diz respeito à capacidade de reprodução. A mulher, depois da menopausa, já não pode mais engravidar - pelo menos sem intervenções tecnológicas. Já o homem pode continuar reproduzindo até os 50, 60 anos, ou mais. Como coloca Badinter (1986. p. 123), "vale lembrar que, apesar da probabilidade da morte do pai quando os 
filhos ainda são muito pequenos, a capacidade de reprodução em qualquer idade confere uma vantagem existencial e importantíssima aos homens".

A alteração dos vínculos entre o público e o privado e a reinvenção dos sentimentos e da intimidade amorosa criam um novo lugar para o indivíduo na arquitetura da família e da sociedade em geral. A própria conceitualização do amor que inclui os aspectos sexuais dentro do matrimônio, diferente da seleção do parceiro unicamente por interesses sociais e econômicos, colocando o casamento como meio privilegiado de obter uma posição social. (BOURDIEU, 2002. p. 145).

Combinar margens de autonomia na esfera familiar cruzando com categorias sociais como classe e gênero pode gerar um olhar específico da atuação dos processos globais de modernização, que não se deram de forma análoga em todos os contextos. $\mathrm{Na}$ verdade, a proposta de uma liberdade amorosa, centrada no indivíduo, não quebrou todas as cadeias de homogamia social, a busca pela igualdade de gênero não acabou com a 'dominação masculina', a separação entre família e produção econômica não fez da primeira apenas um lugar expressivo de manifestação de afeto.

\section{Papéis e Relação de Poder nos Casamentos Interculturais}

No caso dos relacionamentos transnacionais, a relação de poder é desigual e circunscrita por uma soma de categorias como gênero, nacionalidade e mobilidade. Tem-se assim uma mulher brasileira nativa e um homem português imigrante. Entretanto, as relações desiguais são muitas vezes criadas fora da relação a dois, e sentida nas relações sociais mais amplas (família do cônjuge, local de trabalho, instituições, etc.). A própria decisão pessoal de construir um matrimônio parece ser valorizada pela lei, pela sociedade e pelos discursos dominantes no que diz respeito à diferença cultural, limitando o pleno sentido da interculturalidade.

Dessa forma, ao invés da união de dois sujeitos, temos a união de duas nacionalidades. E será que o que motiva essas pessoas a casarem-se reside no fato de possuírem nacionalidades diferentes? E em que medida os discursos dominantes sobre os portugueses e as brasileiras fazem sentido na relação afetiva e sexual?

$\mathrm{O}$ fato de se considerar os casamentos transnacionais como uma eventual estratégia hipergâmica - o casamento com um cidadão "europeu" como forma privilegiada de obter uma posição social e um estatuto jurídico - tem restringido as ponderações sobre esse fenômeno, que na realidade se insere num contexto mais amplo de definições de masculinidade e feminilidade, seja em relação à autonomia, status laboral e dependência econômica e afetiva, como também em relação às opções do mercado matrimonial em que essas pessoas estão circunscritas.

É importante salientar que a diferença, então sublinhada nos casamentos 'interculturais', se inscreve em hierarquias de alteridade que refletirão tanto na relação conjugal como também na definição de papéis de gênero: o homem, imigrante, estrangeiro e a mulher nacional. As expectativas matrimoniais entre homens e mulheres nos casamentos transnacionais têm demonstrado em alguns contextos uma perda da individualização da mulher que pode ser justificada por problemas jurídicos ou institucionais como também pela falta de relações interpessoais (o companheiro passa a ser o único vínculo afetivo), bem como pela dependência econômica. As mulheres sentem-se inseguras, perdendo a autonomia, característica que marcava de alguma forma a sua identidade no contexto do contato. A incorporação de papéis tradicionais femininos dessa forma deve ser levada em consideração, como também as expectativas em relação aos papéis masculinos a serem desempenhados pelos homens estrangeiros.

Kojima (2001) alerta para a possibilidade de construção de um novo sistema global para a divisão reprodutiva e do trabalho. Segundo esse autor, as mulheres nos países industrializados atingiram um nível individual bem-sucedido, libertando-se dos imperativos de se casar e ter filhos, ainda que não tenham conseguido mudar o sistema subjacente do capitalismo e do patriarcado que depende do gênero e do trabalho não remunerado para a reprodução humana e social.

A natureza conceitual, no que diz respeito ao modo de classificar os relacionamentos, estratégias matrimoniais e reprodutivas, renova-se de acordo com a ênfase que se pretende dar ao fenômeno. Os casamentos binacionais não são um modelo recente, mas a globalização, nas suas diversas formas, tem facilitado as reuniões de parceiros de origens diversas. Dois aspectos em particular parecem ser relevantes: o aumento da mobilidade internacional e o intercâmbio cultural internacional. $\mathrm{O}$ aumento das viagens e das migrações internacionais pode ser considerado um importante fator que promove o aumento das relações íntimas, mas a utilização de tecnologias como a internet, sem dúvida, contribui para o aumento do fluxo de informações. 
O papel dos estereótipos na escolha do cônjuge tem sido explorado por diversos autores (VALE DE ALMEIDA, 1998; SALES, 1999; PEREL, 2002; PIERUCCI, 1990; e ORTIZ, 1994), tanto como forma de incentivo à escolha de um estrangeiro - que envolve as suas definições de gênero e os papéis desempenhados no casamento - como na influência na aceitação social do casamento exogâmico e na reação das autoridades.

\section{Turismo Afetivo, Turismo Sexual e as Alterações na Família}

Por outro lado, as profundas alterações sociológicas no domínio da família experimentadas pelas sociedades europeias nas últimas décadas (BERRY BRAZELTON, 1989, SINGLY ,1996; SARACENO e NALDINI, 2003) têm repercutido significativamente na configuração da procura turística, fazendo com que entre os turistas se assista a uma presença crescente daqueles que escapam ao casamento tradicional patriarcal, cujo modelo familiar é formado por pai, mãe, filhos e filhas.

Os turistas jovens do sexo masculino que afluem ao Nordeste brasileiro, muitos deles solteiros ou transitoriamente sem parceira/o sexual, se deslocam frequentemente motivados por um conjunto de representações e expectativas ancoradas em imagens de erotismo e de acesso fácil às práticas sexuais. Considerando que, na economia do turismo, as commodities não possuem apenas valor de uso e de troca, mas também um 'valor-signo', relacionado com a quantidade e a qualidade da experiência que oferecem, elas são fortemente determinadas pelas imagens, publicidade e consumismo que caracterizam as sociedades modernas (BAUDRILLARD, 1981). Por outras palavras, a procura de sexo por parte dos turistas, que parece constituir uma motivação presente em numerosos europeus que visitam o nordeste brasileiro (PISCITELLI, 2004). Durante o dia, muitos turistas aproveitam para recuperar da noite agitada, geralmente marcada por atividade sexual intensa e o consumo em grande quantidade de bebidas alcoólicas, não deixando, todavia, de conviver com as garotas de programa, ora continuando a relação social já estabelecida, ora aproveitando para estabelecer novos contatos.

Estes são realizados quase sempre por iniciativa das jovens nativas, algumas provenientes de outros estados brasileiros, como Paraíba, Ceará, Pernambuco, os mais próximos, ou Maranhão, Pará e Amazonas, os mais distantes. Por norma, a exposição para o turista e a interpelação que se segue é feita de forma mais ou menos sutil: através da postura corporal, do olhar, do sorriso, da solicitação de um cigarro. Como nota Piscitelli (2003. p. 121), estas "[...] aproximações adquirem características de uma paquera [...] remetendo a padrões tradicionais de cortejo".

Os turistas que frequentam a praia de Ponta Negra à procura de aventuras sexuais evidenciam uma considerável diversidade no que diz respeito aos seus países de origem, idades, profissões, motivações, perfis de masculinidade e estrato social, entre outros aspectos. Não há, portanto, um turista típico no quadro do chamado turismo sexual, como por vezes se sugere, quando se diz que os turistas que vêm à procura de sexo são indivíduos sexualmente perturbados. Embora seja inadequado falar-se de um perfil-tipo de turista sexual, existem determinados elementos caracterizadores que sobressaem. Tem-se, assim, o predomínio de turistas de nacionalidade portuguesa, espanhola e italiana, normalmente viajando em grupo (3 a 6 pessoas). Ainda que se encontrem as mais diversas posições de classe, há uma certa preponderância dos indivíduos das classes populares (trabalhadores fabris) e, sobretudo, dos diversos segmentos das classes médias urbanas (empregados do comércio e dos serviços, funcionários públicos, técnicos). São, de um modo geral, homens insatisfeitos com as relações de gênero nos seus contextos de origem, quase sempre motivados pelas representações sociais dominantes sobre a sexualidade da "mulher brasileira", em boa medida amplificadas pelos discursos midiáticos de impacto global e pelas narrativas dos amigos e conhecidos que se envolveram em experiências sexuais com brasileiras em viagens turísticas ao Brasil.

Os entrevistados tendem a estabelecer uma diferenciação bastante vincada entre as mulheres brasileiras e as europeias. Referem-se às brasileiras como mulheres sexualmente mais quentes $\mathrm{e}$ disponíveis para um relacionamento aberto na fase de namoro em favor de uma interação sexual mais imediata e intensa, ainda que não se possa afirmar que a dimensão afetiva não esteja presente. Alguns deles dizem que as europeias são mais frias, mais conservadoras, mais altivas, mais esnobes, sublinhando, sobretudo os italianos, que elas ligam muito à aparência e à capacidade econômica do homem. Apesar desta avaliação desfavorável à europeia, também constatada por Piscitelli (2003), entre os turistas que visitam Fortaleza, são muitos os que admitem preferir casar com uma mulher do seu país em detrimento de uma brasileira, por razões que certamente se prendem com aspectos relacionados com a afinidade cultural e, eventualmente, com os estereótipos da mulher brasileira como sexualmente 
libertina e promíscua.

A maior dificuldade de acesso às mulheres que os turistas gostariam de conquistar nos seus contextos de origem, seja por motivos econômicos, de status ou de apresentação do eu, e o relativo constrangimento em conviver com uma feminilidade ocidental que continua a colocar algumas limitações às preferências e valores predominantes da masculinidade, são dois elementos centrais a considerar para compreender o fenômeno do turismo sexual. (O'CONNELL-DAVIDSON, 1995).

A estes elementos junta-se um terceiro, especialmente válido para os turistas mais velhos, relacionado com expectativas de reviver experiências de homossociabilidade da juventude, ou seja, a procura da recriação dos laços e das vivências masculinas que antecedem a rotina e as responsabilidades da vida adulta. (HEILBORN, 1995).

Para Girona (2007), na produção socioantropológica o turismo sexual é considerado uma expressão das desigualdades que permeiam a 'nova ordem global'. Nesse debate há uma convergência em considerar que o turismo sexual outorga visibilidade às relações entre Norte e Sul, entre privilégios e opressões, pondo em evidência o papel da supremacia masculina Entende-se, aqui, porém, que o turismo sexual apresenta aspectos intrigantes em termos de gênero, particularmente no que se refere à articulação entre gênero e sexualidade, quando se levam em conta as alterações na geografia dessa problemática.

E o que mais despertou a atenção nas entrevistas realizadas em pesquisa de campo foi a quantidade de estrangeiros que, ao viajar, não tinham como objetivo o turismo sexual, nem somente o convencional turismo de lazer, mas sim, o que se denominou de 'turismo afetivo'. Ou seja, buscar em outra cultura um relacionamento afetivo conjugal. Pode-se constatar que os motivos desse último, mesmo que não conscientes a princípio, era o de constituir família, de encontrar alguém que correspondesse ao 'ideal' de casamento vivido pelos seus pais e avós. O casamento liberal, de igual para igual, não os estava satisfazendo. Mesmo não sendo um segmento de turismo, o "turismo afetivo" é uma ação frequente, mesmo que inconsciente, nos turistas que buscam um relacionamento estável em seu período de férias e também em suas viagens seguidas para o mesmo destino, ao longo dos anos, até a decisão de migrar para Natal.

\section{Casais Binacionais Enquanto Sujeitos de Fluxos Migratórios no Nordeste}

O Rio Grande do Norte é hoje um dos mais visitados e promissores destinos turísticos brasileiros. De olho no imenso potencial do turismo potiguar, muita gente tem vindo de outros países não apenas para conhecer, mas também para investir e morar no estado. Dados divulgados em agosto de 2009 pelo Setor de Migração do Departamento da Polícia Federal (DPF/RN), apontam que 6.091 estrangeiros vivem no estado, porque tem residência fixa ou possuem visto temporário mas moram no RN. Esses estrangeiros representam nacionalidades as mais distintas possíveis (a lista divulgada pelo DPF aponta a presença de cidadãos de 19 países diferentes), mas, por ordem decrescente das 5 nacionalidades mais importantes, nota-se a predominância de portugueses (928 imigrantes registrados), seguidos por italianos (775), espanhóis (507), norte-americanos (439) e argentinos (349). O número que se refere apenas aos imigrantes legalizados (que possuem visto de permanência) pode até não ser considerado elevado, mas se torna significativo quando levado em conta o alto poder aquisitivo dos novos moradores, responsáveis pela maioria dos grandes empreendimentos turísticos que estão sendo construídos em território potiguar. Além disso, fica difícil ter a real dimensão do número de estrangeiros que moram no Estado, porque grande parte vive na clandestinidade, segundo depoimento do responsável pelo Setor de Migração da DPF/RN: "Muitos entram no país com visto de turista e quando expira o prazo de permanência eles continuam aqui, trabalhando" (Diário de Natal, 16 ago 2009. p. 16). O que se sabe, contudo, é que esse número não para de crescer. Somente este ano já foram concedidos 431 novos vistos de permanência, sendo a maioria para ficar na capital ou em municípios dos litorais Norte e Sul do estado.

Entre os principais fatores de atração, destaca-se o turismo e a consequente corrida para investimentos imobiliários. Em recente depoimento, o representante de um dos primeiros grupos internacionais a apostar no potencial turístico potiguar, um português, que hoje dirige dois hotéis nas praias de Pipa e Tibau do Sul, vê com naturalidade o crescente número de moradores vindos principalmente da Europa para o estado:

$\mathrm{Na}$ Europa, os investimentos na área de turismo já estão saturados, pois lá a ocupação da atividade é muito intensa e a concorrência entre os grupos é enorme. Diante deste cenário, o Rio Grande do Norte, por todos os seus atrativos, oferece muitas oportunidades para o investidor europeu. (DIÁRIO DE NATAL, 16 ago 2009. p. 16). 
Segundo o mesmo informante, a língua portuguesa seria outro fator de afinidade entre Brasil e Portugal, atraindo grandes contingentes de turistas:

Fizemos, logo que chegamos ao Estado (há quase uma década), um intenso trabalho de divulgação do Rio Grande do Norte em Portugal e hoje praticamente todos os turistas do meu país já visitaram o Estado e alguns acabam ficando para investir ou adquirem uma segunda residência. (DIÁRIO DE NATAL, 16 ago 2009, p. 16).

É importante salientar que nos hotéis administrados pelo mesmo informante, $97 \%$ dos hóspedes são estrangeiros. A maioria dos estrangeiros entrevistados pelo jornalista do Diário de Natal não tinha intenção de morar no Rio Grande do Norte. 'Vim para passar três semanas, mas acabei conseguindo um emprego e já estou há um ano e quatro meses no estado e aqui pretendo ficar', contou um alemão que trabalha hoje como chefe de recepção de um hotel na praia de Tibau do Sul. Uma finlandesa se encantou com o clima e as belezas naturais e resolveu ficar, já que vinha todo ano para o Brasil, de férias, na companhia do marido brasileiro, pois havia comprado imóvel no Rio Grande do Norte. Há nove meses atuando como relações públicas de um resort na praia da Pipa, ela largou a profissão de gerente de loja de confecções na Finlândia para ingressar na atividade turística no Brasil. E garante que não se arrepende.

O gerente e a encarregada de relações públicas, já citados, fazem parte de um grupo de estrangeiros que, apesar de não serem investidores, também vive da atividade turística. Eles saíram de seus países em busca de maior qualidade de vida e de novas oportunidades de trabalho no Rio Grande do Norte. Como o turismo baseado no binômio 'sol e mar' privilegia as áreas do litoral, em Natal, os bairros litorâneos é que recebem os maiores incentivos públicos e privados. Desses bairros, Ponta Negra, situado na Região Administrativa Sul, aparenta ser o local onde os investimentos relacionados ao turismo estão mais presentes e visíveis, com reflexos espaciais marcantes, com a grande presença de pousadas, bares, restaurantes e similares.

Mesmo tendo claro que Natal é o local da pesquisa, acredita-se na necessidade de se conhecer um pouco sobre o lugar. Dessa forma, tentar-se-á descrever, de um modo geral, a cidade de Natal, para que se possa entender o porquê de pessoas saírem de lugares considerados mais desenvolvidos economicamente, como as cidades do Rio de Janeiro e de São Paulo, deixando para trás laços de parentesco e amizade, e recomeçarem a vida num outro lugar, estranho às suas relações familiares e de vizinhança. E mais, de que maneira uma cidade de porte médio como Natal, que, aparentemente, não dispõe de oportunidades que cidades como as citadas anteriormente podem oferecer, conseguiu se encaixar dentro das expectativas e dos esquemas de vida dos estrangeiros que aqui se estabeleceram e que, com exceção de dois, não demonstram intenção de voltar a viver no lugar anterior.

\section{Turismo em Natal: Turismo Afetivo, Turismo Sexual e Relações Sociais Desiguais no Contexto Globalizado}

Antes de se debruçar sobre a questão da conjugalidade, parece oportuno deixar claro qual é o contexto em que se realizou o estudo: de um lado, o turismo enquanto fenômeno macroeconômico resultante de pesados investimentos públicos e privados no Nordeste do Brasil, e particularmente em Natal, desde os anos 80; do outro, a dinâmica do turismo relacionado ao chamado "turismo sexual" e a dimensão (até então oculta) do turismo afetivo. Ambos os fenômenos redundaram na presença crescente de turistas portugueses, espanhóis e italianos, entre outros, no solo potiguar: atraídos por fatores ambientais (o turismo de 'sol e mar'), econômicos (voos charters e regulares em número crescente e pacotes turísticos atrativos para os turistas estrangeiros), culturais (domínio da língua portuguesa ou aculturação facilitada pela origem cultural latina), estruturais (melhoria sensível da infraestrutura hoteleira, turística e urbana em Natal e no litoral norterio-grandense).

A produção socioantropológica internacional mostra um crescente interesse na compreensão da dinâmica das relações sexuais e amorosas estabelecidas no contexto do turismo globalizado, tendo como referência a problemática do turismo sexual e reconhecendo quão recente é esse campo de discussão; entretanto, é escassa em relação ao turismo afetivo.

$\mathrm{Na}$ análise feita por diversos autores (PISCITELLI, 2002 - 2003; GIRONA, 2007), o turismo sexual vem sendo revisitado: abordagens recentes, que incorporam pesquisas centradas nas viagens de mulheres dos países subdesenvolvidos às nações desenvolvidas, tendem a traçar diferenciações entre os estilos de turismo através dos quais homens e mulheres estabelecem relações com nativas/os dos países pobres. Nessas perspectivas, esse turismo é considerado voltado para o 'romance' e caracterizado 
pela ênfase no cortejo e pela construção de relacionamentos duradouros através de um discurso amoroso. Esses aspectos e os traços emocionais presentes nesse tipo de turismo o tornariam diferente do 'turismo sexual'.

Parte-se dessas observações, no encontro entre o debate sobre turismo sexual e turismo afetivo, para mostrar como se desenvolve uma modalidade específica do turismo internacional em Natal, bem como em Fortaleza, Recife, Maceió e outras Capitais do Nordeste. Trata-se, também, de garotas que 'namoram' exclusivamente estrangeiros, mantendo com eles relações carregadas de ambiguidade, muitas vezes duradouras, envolvendo pagamentos cujo valor não é fixo. Neste caso, trata-se de meninas que, com empregos fixos e baixos salários, recebendo presentes e, ocasionalmente, 'ajuda' financeira dos estrangeiros, delimitam diferenças entre elas e as 'moças de programa'. Há, ainda, jovens que saem exclusivamente com estrangeiros, mas não têm qualquer expectativa com relação a dinheiro ou presentes. Elas aspiram penetrar no mundo acessível aos turistas, compartilhando passeios, restaurantes, hotéis. Finalmente, há mulheres, algumas com elevado nível de instrução e, inclusive, profissionais liberais, na faixa dos 30, 40, 50 e 65 anos.

Nesse universo, a 'escolha' de mulheres por parte dos turistas é, muitas vezes, aleatória, e as relações com os visitantes internacionais, associadas à ideia de 'ganhos' diversificados, são almejadas por diferentes categorias de nativas. Essas escolhas recíprocas, atravessadas por distinções de gênero, acionam marcadores de diferença cuja prioridade é estabelecida situacionalmente, num contexto no qual sexualização e racialização estão indissociavelmente ligadas e vinculadas à 'localização'. Argumenta-se que, nesse jogo de diferenciações, a racialização opera através de distinções categóricas, isto é, através de termos de cor que, mais do que descrever, remetem a uma classificação. Argumenta-se, também, e esse é o ponto principal, que há importantes aspectos em comum entre as conceitualizações presentes no procedimento através do qual estrangeiros e nativos racializam/sexualizam as mulheres locais. Entretanto, enquanto na perspectiva dos estrangeiros essas concepções marcam, genericamente, as brasileiras, os nativos as acionam apenas quando as mulheres locais são percebidas como mantendo relações amorosas e sexuais com os visitantes internacionais.

Embora fatores econômicos estejam intimamente vinculados ao desenvolvimento do turismo sexual, os aspectos políticos e culturais, permeados por gênero, são fundamentais para a compreensão da alteração nesses circuitos mundiais.

\section{O Discurso Oficial sobre Turismo no Brasil}

O discurso oficial prega que, através do turismo, haveria um alívio da recessão dos polos receptores de turistas com a criação de empregos, aumento da renda e melhoria no nível de vida. Em contrapartida, o polo emissor de turistas, geralmente grandes cidades, teria, na prática turística (as viagens), um 'alívio' para os seus moradores estressados com todos os problemas do seu cotidiano, ao romper momentaneamente a sua relação com a urbe, buscando novos ambientes para a reposição da energia física e mental.

E o desenvolvimento do turismo no país, assim como nos outros países do chamado mundo tropical, teve na natureza o recurso turístico para ser explorado, adotando-se o binômio "sol e mar", privilegiando assim, como visto, as áreas do litoral. As paisagens que têm como ingredientes sol, céu e água, são aquelas que apresentam ritmo e estilo de vida diferentes do ambiente de trabalho urbano, o que contribui para que sejam as mais procuradas pelo turista na atualidade. Dessa forma, a praia é, disparadamente, a intenção número um de destino turístico, seguida das montanhas, do campo e dos lugares históricos. (CAMARGO, 1999, p. 27).

O Nordeste, conhecido tradicionalmente como 'Região Problema', berço de migrante pobre, que fugia do sol e da seca, passou, desde os anos 80, a se projetar no cenário nacional numa outra perspectiva: a de região turística, denominado de 'paraíso tropical'. Com uma faixa litorânea de, aproximadamente, 3.300 $\mathrm{Km}$ de extensão e sol quase o ano inteiro, o Nordeste passa a produzir e socializar imagens turísticas da região, utilizando-se do mar e do mesmo sol que antes era apontado como 'castigo'. Assim, sua projeção se dá através de um cenário turístico difundido por seus governantes, apoiado por um poderoso marketing. A região se caracteriza, na atualidade (no discurso midiático), não mais pela pobreza, mas pelos seus atrativos turísticos, sobretudo litorâneos, com suas praias ensolaradas de grandes belezas naturais. Daí, para o planejamento e organização do turismo, o Nordeste 'concede' o sol e o mar como a matéria-prima essencial para a composição de uma paisagem perfeita a ser contemplada pelo olhar do turista. Nos anos $80 / 90$, a região Nordeste recebeu muitos recursos em termos de infraestrutura e projetos urbano-turísticos, tais como Rota do Sol - RN, Cabo Branco - PB, Costa Dourada - AL e PE (PAIVA, 1995); e outros estão 
sendo implantados no quadro do Programa de Desenvolvimento do Turismo - PRODETUR e do Programa de Aceleração do Crescimento - PAC do Governo Federal. O turismo passa então a se destacar como uma grande fonte de renda para a região (ANDRADE, 1995).

Natal, capital nordestina de maior índice de crescimento populacional do país, entre os anos 80 e 90, não ficou isolada do novo momento pelo qual passa o Nordeste: o turismo está na ordem do dia. Conhecida como 'A cidade do sol', Natal tem $8 \mathrm{~km}$ de praias urbanas de águas mornas o ano inteiro e pode-se fazer o famoso passeio de buggy nas dunas de Genipabu, no litoral Norte, a poucos quilômetros da cidade. Conta também com 300 dias de sol por ano, um clima tropical úmido e uma temperatura média de $26^{\circ} \mathrm{C}$, atenuados pelos permanentes ventos alísios de Sudeste que sopram do mar e tornam sempre agradáveis os dias e as noites. Some-se a isso o fato de Natal ter a melhor qualidade do ar da América Latina (SEPLAN/IDEC, 1991), além de outras características naturais e o seu patrimônio histórico. Todas essas características têm servido para a produção e veiculação da paisagem natalense como se fosse um verdadeiro paraíso.

Para viabilizar a produção e venda da paisagem de Natal, o governo do RN, em 1978, implantou o Plano Urbano Turístico para a construção da Via Costeira através da Secretaria Estadual de Planejamento (SEPLAN). A Via Costeira é considerada o marco de desenvolvimento do turismo em Natal. Foi nos anos 80 que a cidade começou a ganhar notoriedade em relação ao turismo regional e nacional. Nesse período, Natal, assim como as áreas litorâneas do Estado, incorpora-se ao Programa para o Desenvolvimento do Turismo no Nordeste (PRODETUR-NE). A partir daí, o desenvolvimento do turismo, não só em Natal, mas nas áreas litorâneas, vem sendo fomentado pelo Projeto Rota do Sol, que faz parte do PRODETUR-NE. Esse programa tem como meta principal montar uma infraestrutura satisfatória para o empreendimento de atividades turísticas e consolidar um polo turístico no Estado. (MARCELINO, 1996).

Em um primeiro momento, a concentração de investimentos em Natal decorre do fato de ela ser a principal cidade do estado e de haver um grande número de turistas que aqui aportam, tornando-a um polo. Essa posição privilegiada intensifica-se pelo fato de o polo ter sido eleito pioneiro, pelo Banco do Nordeste do Brasil, para implantação do Programa Polos de Desenvolvimento Integrado de Turismo, devido ao seu fluxo turístico de 1991-1999.

\section{Referências}

ANDRADE, Manoel Correa de. Estado, capital e industrialização no Nordeste. Rio de Janeiro: Zahar, 1995.

BADINTER, Elizabeh. Um é o outro: relações entre homens e mulheres. Rio de Janeiro: Nova Fronteira, 1986 .

BAUDrIllard, Jean. A Sociedade de Consumo. Lisboa: Ed. 70, 1981.

BERQUÓ, Elza. A família no século XXI: um enfoque demográfico. Revista Brasileira de Estudos de População. vol. 6, nº 2, p. 1-16, jul./dez., 1989.

BERRY-BRAZELTON. Thomas. La famile em crise. Paris: Stock, 1989.

BOURDIEU, Pierre. A Dominação Masculina. Rio de Janeiro: Bertrand, 2002.

CAMARGO, Luis O. Lima. O que é Lazer. São Paulo: Brasiliense, 1999.

CARVAlHO FILHO, Benedito José de. Marcas de Família: travessias no tempo. São Paulo: Annablume / Fortaleza: Secretaria da Cultura e Desporto do Governo do Estado do Ceará, 2000.

DIÁRIO DE NATAL. Natal, uma doce paixão alémmar. 16 ago, 2009, p. 16.

GIRONA, Jordi. Amor importado, migrantes por amor: La constitución de parejas entre espanoles y mujeres de América latina y de Europa del Este en el marco de la transformación actual deI sistema de género en España. Proyectos de Investigación Científica y Desarrollo Tecnológico, 2007.

GOLDANI, Ana Maria. As Famílias no Brasil Contemporâneo e o Mito da Desestruturação. Cadernos Pagu. De Trajetórias e Sentimentos, n. 1, p. 67-110 1993.

GOLDENBERG, Mírian. Ser homem, ser mulher: Dentro e fora do Casamento. Rio de Janeiro: Estudos Antropológicos / Revan, 1991.

HEILBORN, Maria Luiza. O que faz um Casal, Casal? Conjugabilidade, Igualitarismo e Identidade Sexual em Camadas Médias Urbanas". In: HEILBORN, Maria Luiza. Famílias em Processos Contemporâneos: 
Inovações Culturais na Sociedade Brasileira. São Paulo: Loyola, 1995.

INSTITUTO BRASILEIRO DE GEOGRAFIA E ESTATÍSTICA - IBGE. Censo demográfico 2000. Rio de Janeiro: IBGE, 2002.

INSTITUTO BRASILEIRO DE GEOGRAFIA E ESTATÍSTICA. (PNAD 1999 e CENSO 1995/2000/2002).

JABLONSKI, Bernardo. A Difícil Extinção do Boçalossauro. In: NOLASCO, Socrates. (Org.). A Desconstrução do Masculino. Rio de Janeiro: Rocco, 1995.

KOJIMA, Yu. In the business of cultural reproduction: Theoretical implications of the mail-order bride phenomenon. Women's Studies International Forum, vol. 24, p. 199-210, 2001.

MARCELINO, Ana Maria Teixeira. O turismo e sua influência na ocupação do espaço litorâneo. In: RODRIGUES, Adir A B. (org.) Turismo e geografia: reflexões teóricas e enfoques regionais. São Paulo: Hucitec, 1996, p. 177-183.

NICOLACI-DA-COSTA, Ana. Maria. Mal-estar na Família: Descontinuidade e Conflito entre Sistemas Simbólicos? In: FIGUEIRA, Sérvulo. A. (Org). Cultura da Psicanálise. São Paulo: Brasiliense, 1985.

O'CONNELL-DAVIDSON, Julia. British sex tourists in Thailand. In: MAYNARD, Mary.; PURVIS, June. (Org). (Hetero) sexual politics. Londres: Taylor \& Francis, 1995.

PIERUCCI, Antonio Filho. Ciladas da Diferença. Revista de Sociologia da USP, Tempo Social, 2. sem. 1990. p.7-33

PISCITELLI, Adriana. Entre a Praia de Iracema e a União Européia: Turismo sexual internacional exotismo e autenticidade: relatos de viajantes à procura de sexo. In: SILVA, Maria Cardeira da (Org.). Outros trópicos: novos destinos turísticos, novos terrenos da antropologia. Lisboa: Livros Horizonte, 2004.

PISCITELLI, Adriana. Sexualidade tropical em contextos de Primeiro Mundo. Migração de Brasileiras para a Itália no contexto da Transnacionalização do mercado sexual. Campinas: UNICAMP, 2003.
SALES, Teresa. Brasileiros longe de casa. São Paulo: Cortez, 1999.

SEPLAN / IDEC. NASA-INPE apud RIO GRANDE DO NORTE, 1991.

POLÍTICA DE TURISMO DO ESTADO DO RIO GRANDE DO NORTE. Municípios em destaque, Natal. v. 18, n. 72, p. 46-47, 1997.

VAISTMAN, Jeni. Flexíveis e Plurais: Identidade, Casamento e Família em Circunstâncias PósModernas. Rio de Janeiro: Rocco, 1994.

ZAMBERLAM, Cristina de Oliveira. Os novos paradigmas da família contemporânea: uma perspectiva interdisciplinar. Rio de Janeiro: Renovar, 2001.

Recebido em 17 de junho de 2010. Aceito em 07 de maio de 2011.

\section{Maria das Graças Lucena de Medeiros}

